\title{
Vorwort zur zwölften Auflage.
}

Am 9. August $191 \mathrm{y}$ hat $\mathrm{Ernst} \mathrm{H}$ a $\mathrm{c} \mathrm{ckel}$ dip Feder aus der müden Hand gelegt und die Augen für immer geschlossen. Wenige Wochen vorher war ihm noch die Freude beschieden gewesen, zu hören, daß von seiner "Natürlichen Schöpfungsgeschichte" eine neue Auflage nötig sei. Selbst nicht mehr imstande, die Neuausgabe zu besorgen, übertrug er diese Arbeit dem Unterzeichneten. In eingehenden Überlegungen und $\mathbf{E r}$. örterungen wurde von dem Meister und seinem Schüler die Frage erwogen, ob und welche Änderungen etwa vorzunehmen scien Wir kamen endlich zu dem Entschluß, das Buch mit geringen Ânderungen $80 \mathrm{zu}$ lassen, wie es in der zehnten und elften Auflage erschienen war.

Die "Natürliche Schöpfungsgeschichte" gehört zu den klassischen Büchern der Entwicklungslehre. Sie war es, die dem Entwicklungsgedanken und der darauf gegründeten Weltanschauung in hartem Widerstande Bahn brach. Sie war es, die den Namen Er n s t $\mathbf{H}$ a e c k e l zuerst in alle Welt hinaus trug, und weit über die gelehrten Kreise hinaus, hinein ins Volk Sie war es, die dem Denken einer ganzen Generation das Gepräge gab und damit anch den Grund legte zum Bauen über sich selbst hinaus. Den Fortschritten der Erkenntnis entsprechend stetig vermehrt und verbessert, vertritt sie in ihrer letzten (elfteni) Auflage den Standpunkt, den Ernst Haeckel am Ende seiner wissenschaftlichen Laufbahn eingenommen hat. So mag sie noch einmal hinausgehen als ein lebendiges Denkmal seines kühnen Geistes und auch weiterhin anregen zu kühnem Denken. das seine überzeugende Kraft aus dem unerschöpflichen Tat. sachenschatze der Naturwissenschaft gewinnt und in höchsten Ideen und Idealen dem Wollen Bahn und Richtung bestimmt

Einem ausdrücklichen Wunsche meines lieben Meisters komme ich nach, wenn ich an dieser Stelle auf meine „Geschichte der Entwicklungslehre" hinweise (Alfred Kröner Verlag, Leipzig 1918), die es unternimmt, das Werden des Entwicklungsgedankens im Gesamtgebiete der Naturwissenschaften darzustellen.

Jena Ernst Haeckel-Archiv, 9 August 1920

Heinrich Schmidt. 